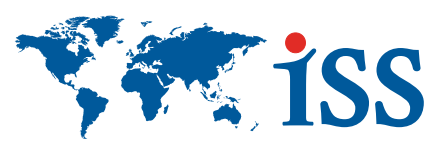

Institute of Social studies

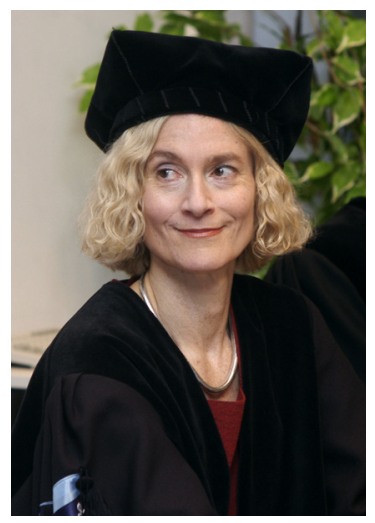

\title{
Education for Democratic Citizenship
}

\author{
Martha Nussbaum \\ Professor of Law and Ethics \\ at the University of Chicago Law Faculty \\ Honorary Fellow Institute of Social Studies
}

Lecture delivered on the occasion of the awarding of the degree of Doctor Honoris Causa at the Institute of Social Studies, The Hague, The Netherlands, 9 March, 2006. 

It is an enormous honor to accept this honorary doctorate from the Institute of Social Studies. I have for some time had enormous admiration for the public culture of philosophy in The Netherlands, and this wonderful Institute provides a good deal of the impetus for reflections about social justice and human flourishing that take place in this country. I thank you most humbly and sincerely. Because my argument will connect democratic education closely to emotional and imaginative cultivation, let me begin my talk with an example from ancient Athenian tragedy, the ending of Euripides' The Trojan Women.

The towers of Troy are burning. All that is left of the once-proud city is a group of ragged women, bound for slavery, their husbands dead in battle, their sons murdered by the conquering Greeks, their daughters raped. Hecuba their queen invokes the king of the gods, using, remarkably, the language of democratic citizenship: "Son of Kronus, Council-President of Troy, father who gave us birth, do you see these undeserved sufferings that your Trojan people bear?" The Chorus answers grimly, "He sees, and yet the great city is no city. It has perished, and Troy exists no longer." A little later, Hecuba herself concludes that the gods are not worth calling on, and that the very name of her land has been wiped out.

In one way, the ending of this drama is as bleak as any in the history of tragic drama. Death, rape, slavery, fire destroying the towers, the city's very name effaced from the record of history by the acts of rapacious and murderous Greeks. And yet, of course, it did not happen that way, not exactly. For the story of Troy's fall is being enacted, some six hundred years after the event, by a company of Greek actors, in the Greek language of a Greek poet, in the presence of all the adult citizens of Athens, most powerful of Greek cities. Hecuba's cry to the gods even imagines him as a peculiarly Athenian type of civic official, president of the city council. So the name of the land didn't get wiped out after all. The imaginations of the conquerors were haunted by it, transmitted it, and mourn it. Obsessively their 
arts repeat the events of long-ago destruction, typically inviting, as here, the audience's compassion for the women of Troy and blame for their assailants. In its very structure the play makes a claim for the moral value of compassionate imagining, as it asks its audience to partake in the terror of a burning city, of murder and rape and slavery. Insofar as members of the audience are engaged by this drama, feeling fear and grief for the conquered city, they demonstrate the ability of compassion to cross lines of time, place, and nation - and also, in the case of many audience members, the line of sex, perhaps more difficult yet to cross.

Nor was the play an aesthetic event cut off from political reality. The dramatic festivals of Athens were sacred festivals strongly connected to the idea of democratic deliberation, and the plays of Euripides were particularly well known for their engagement with contemporary events. In this case, the audience that watched The Trojan Women had recently voted to put to death the men of the rebellious colony of Melos and to enslave the women and children. Euripides invites them to contemplate the real human meaning of their actions. Compassion for the women of Troy should at least cause moral unease, reminding Athenians of the full and equal humanity of people who live in distant places, their fully human capacity for suffering.

But did those imaginations really cross those lines? Think again of that invocation of Zeus. Trojans, if they worshipped Zeus as king of gods at all, surely did not refer to him as the president of the city council. The term prytanis is an Athenian legal term, completely unknown elsewhere. So it would appear that Hecuba is not a Trojan but a Greek. Her imagination is a Greek democratic (and, we might add, mostly male) imagination. Maybe that's a good thing, in the sense that the audience is surely invited to view her as their fellow and equal. But it still should give us pause. Did compassion really enable those Greeks to reach out and think about the real humanity of others, or did it stop short, allowing them to reaffirm the essential Greekness of everything that's human? Of course compassion 
required making the Trojans somehow familiar, so that Greeks could see their own vulnerability in them. But it's so easy for the familiarization to go too far: they are just us, and we are the ones who suffer humanly. Not those other ones, over there in Melos.

The democratic imagination is powerful but flawed. As in ancient Athens, so too now, democratic citizens often think well together about common problems, even problems involving people in distant nations with whom they have dealings. The imagination has a powerful capacity to imagine the sufferings and needs of people at a distance, and at least in principle it can usefully inform public debate about policy. But the Hecuba example shows that this imagination also has limits. It can be self-serving, imagining one's own nation as the source of all human values and dehumanizing other cultures in consequence. Democratic citizens can also fail to think critically about what they hear, putting anger, fear, and power ahead of reason. Thucydides' history of the Peloponnesian War shows many instances of this failing - not least in the debate about Mytilene, another defeated colony that, like Melos, had rebelled against Athens. Swayed by the powerful but highly irrational rhetoric of politician Cleon, the people voted to put to death all the men of the colony and to enslave the women and children. They sent a ship to execute the grim command. Then, after hearing a well-argued and persuasive speech by Diodotus, they changed their mind, and sent a second ship to cancel the order of death. It was only by sheer chance, because the first ship was stalled at sea by a windless spell, that the second ship caught the first and lives were spared. So the democratic mind is also careless, prone to hasty and irrational thinking.

All modern democracies, like ancient Athens but even more so, are part of an interlocking world, a world that makes decisions not only about internal matters but also about the life and death of strangers. It is a world of staggering inequalities. The life expectancy at birth of a child born in the United States is about 78 years. In Sierra Leone, life expectancy at birth is about 38 years. How can we educate demo- 
cratic citizens who think well about these inequalities, understanding the reality of distant lives without making the errors that Euripides and Thucydides so vividly depicted? I shall now argue that the educational concepts of the ancient Greek philosophers, in particular Socrates and the Greek and Roman Stoics, give us a great deal of help in solving this problem.

What I am about to propose is a concept of what is often called "liberal education." The very term "liberal education" derives from the Roman Stoic philosopher Seneca, who was also a leading politician, in an era of great anxiety and conflict. So let me begin with his reflections, which are continuous, as we'll soon see, with the practice of Socrates, as well as the ideas of the older Greek Stoics. In the letter that invents our modern concept of liberal education, Seneca begins by describing the usual style of Roman education, noting that it is called "liberal" (liberalis, "connected to freedom"), because it is understood to be an education for well-brought-up young gentlemen, who were called the liberales, the "free-born." It was an acculturation into Roman traditions, in which young people simply absorbed received values. He himself, he now announces, would use the term "liberal" in a very different way. In his view, an education is truly "liberal" only if it is one that "liberates" the student's mind, encouraging him or her to take charge of his or her own thinking, leading the Socratic examined life and becoming a reflective critic of traditional practices. (I say "him or her" not just out of contemporary political correctness: Stoic philosophers of the first century AD wrote at length about the equal education of women, and defended the radical view that women as much as men should lead the examined life.) Seneca goes on to argue that only this sort of education will develop each person's capacity to be fully human, by which he means self-aware, self-governing, and capable of respecting the humanity of all our fellow human beings, no matter where they are born, no matter what social class they inhabit, no matter what their gender or ethnic origin. "Soon we shall breathe our last," he concludes in his related treatise 
On Anger. "Meanwhile, while we live, while we are among human beings, let us cultivate our humanity."

This concept of a link between liberal education and a deeper and more inclusive kind of citizenship has a special urgency in our times, as the global market is increasingly putting pressure on all humanistic ideas in education, as educational proposals based on technical ability alone are becoming increasingly popular. When education is discussed in most modern democracies, the focus is on education for profitability in the global market, and we rarely see a focus on the education of the imagination and the critical faculties. But these abilities are crucial to the health of democracy: so we need the ideas of the ancient Greeks and Romans more than ever.

I have argued, in a book called Cultivating Humanity, that three capacities, above all, are essential to the cultivation of humanity in today's world, and for the health of democratic citizenship. First is the capacity for critical examination of oneself and one's traditions -- for living what, following Socrates, we may call "the examined life." This means a life that accepts no belief as authoritative simply because it has been handed down by tradition or become familiar through habit, a life that questions all beliefs and accepts only those that survive reason's demand for consistency and for justification. Training this capacity requires developing the capacity to reason logically, to test what one reads or says for consistency of reasoning, correctness of fact, and accuracy of judgment. Testing of this sort frequently produces challenges to tradition, as Socrates knew well when he defended himself against the charge of "corrupting the young." But he defended his activity on the grounds that democracy needs citizens who can think for themselves rather than simply deferring to authority, who can reason together about their choices rather than just trading claims and counter-claims. Like a gadfly on the back of a noble but sluggish horse, he said, he was waking democracy up so that it could conduct its business in a more reflective and reasonable way. Our democracy, like ancient Athens, is prone to hasty and 
sloppy reasoning, and to the substitution of invective for real deliberation. We need Socratic teaching to fulfill the promise of democratic citizenship. Schools that help young people speak in their own voice and to respect the voices of others will have done a great deal to produce thoughtful and potentially creative democratic citizens, citizens who can understand Hecuba's suffering without imposing on it their own schemes of domination.

Citizens who cultivate their humanity need, further, my second element, an ability to see themselves as not simply citizens of some local region or group but also, and above all, as human beings bound to all other human beings by ties of recognition and concern: as "citizens of the world," as the ancient Greco-Roman tradition that Seneca belonged to expressed the idea. Cultivating our humanity in a complex interlocking world involves understanding the ways in which common needs and aims are differently realized in different circumstances. This requires a great deal of knowledge that students in Europe and North America rarely got in previous eras, knowledge of non-Western cultures, and also of minorities within their own, of differences of gender, race, and sexuality. In the years since I wrote the book, there has been great progress integrating the study of race and gender into undergraduate curricula of many kinds. There has been much less progress conveying an adequate understanding of the reality of an interlocking world order. Students should begin very early to learn the rudiments of world history, and to gain a basic understanding of the major world religions. It is easier to do this if one begins when children are young, so that they come to see the world - and their own nation itself -- as complex and heterogeneous rather than as local and homogeneous.

But, now, let me turn to the third part of my proposal. Citizens cannot think well on the basis of factual knowledge alone. The third ability of the citizen, closely related to the first two, can be called the narrative imagination. This means the ability to think what it might be like to be in the shoes of a person different from oneself, to be an 
intelligent reader of that person's story, and to understand the emotions and wishes and desires that someone so placed might have. That is why I began this talk with Hecuba and why I have focused throughout on the development of capacities for imaginative and emotional understanding, capacities that we associate with literature and the other arts. The cultivation of sympathy, which I take to be the central public task of ancient Athenian tragedy, has also been a key part of the best modern ideas of progressive education. The great John Dewey long ago argued that the arts were modes of intelligent perception and experience that should play a crucial role in education, forming the civic imagination. He protested against the usual sort of education, in which "Achievement comes to denote the sort of thing that a wellplanned machine can do better than a human being can." Similarly, in India, the distinguished poet and educator Rabindranath Tagore wrote, concerning the role of the arts in his school at Santiniketan, "We may become powerful by knowledge, but we attain fullness by sympathy...But we find that this education of sympathy is not only systematically ignored in schools, but it is severely repressed." The education of sympathy is being repressed once again today, as arts and humanities programs are increasingly being cut back in schools in many nations, in favor of a focus on technical and scientific education, which is seen as the key to a nation's financial success.

Courses in literature and the arts can cultivate sympathy in many ways, through engagement with many different works of literature, music, fine art, and dance. But my example from Euripides suggests that thought needs to be given to what the student's particular blind spots are likely to be, and texts should be chosen in consequence. For all societies at all times have their particular blind spots, groups within their culture and also groups abroad that are especially likely to be dealt with ignorantly and obtusely. Works of art can be chosen to promote criticism of this obtuseness, and a more adequate vision of the unseen. Ralph Ellison, in a later essay about his great novel Invisible Man, wrote that a novel such as his could be "a raft of perception, hope, and entertainment" on which American culture could 
"negotiate the snags and whirlpools" that stand between us and our democratic ideal. His novel, of course, takes the "inner eyes" of the white reader as its theme and its target. The hero is invisible to white society, but he tells us that this invisibility is an imaginative and educational failing on their part, not a biological accident on his. Through the imagination we are able to have a kind of insight into the experience of another group or person that it is very difficult to attain in daily life -- particularly when our world has constructed sharp separations between groups, and suspicions that make any encounter difficult.

So we need to cultivate our students' "inner eyes," and this means carefully crafted courses in the arts and humanities, which bring students into contact with issues of gender, race, ethnicity, and cross-cultural experience and understanding. This artistic instruction can and should be linked to the "citizen of the world" instruction, since works of art are frequently an invaluable way of beginning to understand the achievements and sufferings of a culture different from one's own.

The arts are also crucial sources of both freedom and community. When people put on a play together, they have to learn to go beyond tradition and authority, if they are going to express themselves well. And the sort of community created by the arts is non-hierarchical, a valuable model of the responsiveness and interactivity that a good democracy will also foster in its political processes. When I talked to the late Amita Sen, who danced in Rabindranath Tagore's dancedramas, first in his progressive school in Santiniketan and then on the Kolkata stage, I see the revolutionary nature of what Tagore had done for young women in particular, urging them to express themselves freely through their bodies and to join with him in a kind of profoundly egalitarian play. The scandal of this freedom, as young women of good family suddenly turned up on the Kolkata stage, shook convention and tradition to their foundations. 
Finally, the arts are great sources of joy for children, and indeed for adults as well. Participating in plays, songs, and dances fills children with joy, and this joy carries over into the rest of their education. Amita Sen's book about Tagore as choreographer is aptly entitled, in English, Joy in All Work, and it shows how all the "regular" education in Santiniketan, the education that enabled these students to perform very well in standard examinations, was infused with passion and delight because of the way in which education was combined with dance and song. Children do not like to sit still all day; but they also do not know automatically how to express emotion with their bodies in dance. Tagore's extremely expressive, but also extremely disciplined dance regime was an essential source of creativity, thought, and freedom for all pupils, but particularly, perhaps, for women, whose bodies had been taught to be shame-ridden and inexpressive. This is her general description of what Tagore was trying to convey for and with children through dance:

His dance was a dance of emotion. The playful clouds in the sky, the shivering of the wind in the leaves, light glistening on the grass, moonlight flooding the earth, the blossoming and fading of flowers, the murmur of dry leaves - the pulsing of joy in a man's heart, or the pangs of sorrow, are all expressed in this expressive dance's movements and expressions. ${ }^{i}$

We should bear in mind that we hear the voice of an older woman recalling her childhood experience. How extraordinary that the emotions and the poetry of the child live on so vigorously in the woman, and what a tribute this is to the capacity of this sort of education for a kind of enlivening of the imagination that continues on in one's life when all specific learned facts are forgotten. Furthermore, Amita Sen makes it perfectly clear that the dance experience was itself highly

i. Amita Sen, Joy in All Work, 35 
disciplined and a fine source of the understanding of discipline for children, and at the same time closely interwoven with learning of more traditional types, not just a kind of distracting fun and games.

There is a further point to be made about what the arts do for the spectator. As Tagore knew, and as radical artists have often emphasized, the arts, by generating pleasure in connection with acts of subversion and cultural criticism, produce an endurable and even attractive dialogue with the prejudices of the past, rather than one fraught with fear and defensiveness. That is what Ellison meant by calling Invisible Man "a raft of perception, hope, and entertainment" that could help the American democracy "negotiate the snags and whirlpools" that stand between it and "the democratic idea." Entertainment is crucial to the ability of the arts to offer perception and hope. It's not just the experience of the performer, then, that is so important for democracy, it's the way in which performance offers a venue for exploring difficult issues without crippling anxiety.

How are the abilities of citizenship doing in the world today? Very poorly, I fear. Education of the type I recommend is doing quite well in the place where I first studied it, namely the liberal arts portion of U. S. college and university curricula. Indeed, it is this part of the curriculum, in institutions such as my own, that particularly attracts philanthropic support, as rich people remember with pleasure the time when they read books that they loved, and pursued issues open-endedly.

Outside the U. S., many nations whose university curricula do not include a liberal arts component are now striving to build one, since they acknowledge its importance in crafting a public response to the problems of pluralism, fear, and suspicion their societies face. I've been involved in such discussions in the Netherlands, in Sweden, in India, in Germany, in Italy, in India and Bangladesh. Whether reform in this direction will occur, however, is hard to say: for liberal education has high financial and pedagogical costs. Teaching of the sort I 
recommend needs small classes, or at least sections, where students get copious feedback on frequent writing assignments. European professors are not used to this idea, and would at present be horrible at it if they did try to do it, since they are not trained as teachers in the way that U. S. graduate students are, and come to expect that holding a chair means not having to grade undergraduate writing assignments. Even when faculty are keen on the liberal arts model, bureaucrats are unwilling to believe that it is necessary to support the number of faculty positions required to make it really work. Thus, at the University of Oslo a compulsory ethics course has been introduced for all first-year students, but it is taught as a lecture course with 500 people, and a multiple-choice examination at the end. This is worse than useless, since it gives students the illusion that they have actually had some philosophical education, when they have had only a gesture towards such an education. In Sweden, at the new urban university Sodertorn's Hogskola, a large proportion of whose students are immigrants, the faculty and the Vice-Chancellor badly want a liberal arts curriculum based on the idea of preparation for democratic citizenship. They have sent young faculty to U. S. liberal arts colleges to study and practice this type of small-classroom teaching, and they have constructed an exciting course on democracy. As yet, however, they do not have enough manpower to hold the class in small sections with lots of group discussion and copious writing assignments, something that is crucial if the class is to succeeed. Only in small idiosyncratic institutions, such as the Institute for Humanist Studies in Utrecht, is the liberal arts idea a reality in Europe.

Another problem that European universities have is that new disciplines of particular importance for good democratic citizenship have no secure place in the structure of undergraduate education. Women's Studies, the study of race and ethnicity, Judaic studies, Islamic studies - all these are likely to be marginalized, catering only to the student who already knows a lot about the area and who wants to focus on it. In the liberal arts system, by contrast, such new disciplines can provide courses that all undergraduates are required to take, and can 
also enrich the required liberal arts offerings in other disciplines, such as literature and history. Where there are no such requirements, the new disciplines remain marginal.

So the universities of the world have great merits, but also great problems. By contrast, the abilities of citizenship are doing very poorly, in every nation, in the most crucial years of childrens' lives, the years known as $\mathrm{K}$ through 12 . Here the demands of the global market have made everyone focus on scientific and technical proficiency as the key abilities, and the humanities and the arts are increasingly perceived as useless frills, which we can prune away to make sure our nation (whether it be India or the U. S.) remains competitive. To the extent that they are the focus of national discussion, they are recast as technical abilities themselves, to be tested by quantitative multiplechoice examinations, and the imaginative and critical abilities that lie at their core are typically left aside. At one time, Dewey's emphasis on learning by doing and on the arts would have been second nature in any American elementary school. Now it is under threat even at the Dewey Laboratory School. National testing has already made things worse in the U. S. , as national testing usually does: for at least my first and third ability are not testable by quantitative multiple choice exams, and the second is very poorly tested in such ways. (Moreover, nobody bothers to try to test it even in that way.) Whether a nation is aspiring to a greater share of the market, like India, or struggling to protect jobs, like the U. S., the imagination and the critical faculties look like useless paraphernalia, and people even have increasing contempt for them.

Thus the humanities are turned into rapid exercises in rote learning, packaged, often, in state-approved textbooks, and the whole political debate comes to be focused on the content of these textbooks, rather than on the all-important issue of pedagogy. At this point I cannot resist introducing the great educator Rabindranath Tagore's short story, called "The Parrot's Training," which provides a very good picture of education in our time, as in his. (Tagore briefly went to 
several schools, but he detested the school experience and left as soon as he could.)

A certain Raja had a bird whom he loved. He wanted to educate it, because he thought ignorance was a bad thing. His pundits convinced him that the bird must go to school. The first thing that had to be done was to give the bird a suitable edifice for his schooling: so they build a magnificent golden cage. The next thing was to get good textbooks. The pundits said, "Textbooks can never be too many for our purpose." Scribes worked day and night to produce the requisite manuscripts. Then, teachers were employed. Somehow or other they got quite a lot of money for themselves and built themselves good houses. When the Raja visited the school, the teachers showed him the methods used to instruct the parrot. "The method was so stupendous that the bird looked ridiculously unimportant in comparison. The Raja was satisfied that there was no flaw in the arrangements. As for any complaint from the bird itself, that simply could not be expected. Its throat was so completely choked with the leaves from the books that it could neither whistle nor whisper."

The lessons continued. One day, the bird died. Nobody had the least idea how long ago this had happened. The Rajah's nephews, who had been in charge of the education ministry, reported to the Raja: "Sire, the bird's education has been completed.'

'Does it hop?' the Raja enquired.

'Never!' said the nephews.

'Does it fly?'

'No.'

'Bring me the bird,' said the Raja.

The bird was brought to him, guarded by the kotwal and the sepoys and the sowars. The Raja poked its body with his finger. Only its inner stuffing of book-leaves rustled. 
Outside the window, the murmur of the spring breeze amongst the newly budded asoka leaves made the April morning wistful.ii

This wonderful story hardly needs commentary. Its crucial point is that educationists tend to enjoy talking about themselves and their own activity, and to focus too little on the small tender children whose eagerness and curiosity should be the core of the educational endeavor. Tagore thought that children were usually more alive than adults, because less weighted down by habit. The task of education was to avoid killing off that curiosity, and then to build outward from it, in a spirit of respect for the child's freedom and individuality rather than one of hierarchical imposition of information.

I do not agree with absolutely everything in Tagore's educational ideal. For example, I am less anti-memorization than Tagore was. Memorization of fact can play a valuable and even a necessary role in giving pupils command over their own relationship to history and political argument. That's one reason why good textbooks are important, something that Tagore would have disputed. But about the large point I am utterly in agreement: education must begin with the mind of the child, and it must have the goal of increasing that mind's freedom in its social environment, rather than killing it off. (I note that good nongovernmental organizations that conduct literacy programs for women and girls in India, a large part of what I have studied, do everything Tagore would have wanted and everything that my threepart structure recommends. They do not fall victim to rote learning, because they know that their students won't stay around unless education is enlivening, and they use the arts and literature very productively to stimulate criticism of imprisoning traditions.

ii. From V. Bhatia, ed., Rabindranath Tagore: Pioneer in Education (New Delhi: Sahitya Chayan, 1994 
But now to return to Europe: Only if these three abilities are cultivated at all levels, I believe, will the democracies of Europe be able to weather the crisis of fear and suspicion that is currently besetting them. Curricula need to be radically rethought with these functions in mind. Particularly at the university level, such changes will involve very great upheaval. The price of not facing the difficulty of change, however, will be an impoverished dialogue between groups and individuals, and dialogue is absolutely crucial to the future of the European democracies.

Let me now return to the example from Greek tragedy with which I began, drawing together these ruminations about democratic education with my problems about compassion and the tragic imagination. As Hecuba's example shows, democracies have great rational and imaginative powers. They also are prone to some serious flaws in reasoning, to parochialism, haste, sloppiness, selfishness. Education based mainly on profitability in the global market magnifies these deficiencies, producing a greedy obtuseness that threatens the very life of democracy itself. We need to listen, once again, to the ideas of Socrates and Seneca, and to the related modern ideas of Dewey and Tagore, favoring an education that cultivates the critical capacities, that fosters a complex understanding of the world and its peoples, and that educates and refines the capacity for sympathy - in short, an education that cultivates human beings and their humanity, rather than producing generations of useful machines. If we do not insist on the crucial importance of the humanities and the arts, they will drop away, because they don't make money. They only do what is much more precious than that, make a world that is worth living in, and democracies that are able to overcome fear and suspicion and to generate vital spaces for sympathetic and reasoned debate. 